\title{
AVALIAÇÃO AGRONÔMICA DO CULTIVO DE MILHO EM DIFERENTES NÍVEIS DE INVESTIMENTO
}

\author{
Agronomic evaluation of maize crop at different levels of investment
}

\author{
Renzo Garcia Von Pinho', Antonio Ariel Canedo Rivera² ${ }^{2}$ André Hunberto de Brito ${ }^{3}$, Tiago Geraldo de Lima ${ }^{3}$
}

\begin{abstract}
RESUMO
Com o objetivo de avaliar o desempenho agronômico de nove cultivares de milho, sendo cinco destinadas ao cultivo com baixo investimento e quatro cultivares destinadas ao cultivo sob condições de alto investimento, foram conduzidos dois experimentos no ano agrícola 2004/2005, em Lavras, MG. Em um dos experimentos, utilizou-se a densidade de semeadura de 55.000 plantas ha $^{-1}$ e, no outro, 65.000 plantas ha-1. Em cada experimento, as nove cultivares de milho foram avaliadas em três níveis de adubação: (1) $300 \mathrm{~kg}$ ha $^{-1}$ de 8-28-16 na semeadura, mais $200 \mathrm{~kg} \mathrm{ha}^{-1}$ de 30-00-20, em cobertura; (2) $400 \mathrm{~kg} \mathrm{ha}^{-1}$ de 8-28-16 na semeadura, mais $300 \mathrm{~kg}$ ha${ }^{1}$ de 30-00-20, em cobertura e (3) $500 \mathrm{~kg} \mathrm{ha}^{-1} \mathrm{de}$ 8-28-16 na semeadura, mais $300 \mathrm{~kg} \mathrm{ha}^{-1} \mathrm{de} 30-00-20$ e $150 \mathrm{~kg} \mathrm{ha}^{-1}$ de uréia, em cobertura. Os resultados permitiram concluir que a adubação de $500 \mathrm{~kg} \mathrm{ha}^{-1}$ de 8-28-16 na semeadura, mais $300 \mathrm{~kg} \mathrm{ha}^{-1}$ de $30-00-20$ na primeira cobertura e $150 \mathrm{~kg} \mathrm{ha}^{-1}$ de uréia na segunda cobertura proporciona aumento significativo na produtividade de grãos e na altura das plantas. O aumento da densidade de semeadura de 55.000 plantas ha $^{-1}$ para 65.000 plantas ha $^{-1}$ não influenciou a produtividade de grãos, mas, interferiu na altura de plantas e de espigas e na prolificidade. As cultivares destinadas ao alto investimento apresentam maior prolificidade, maior altura de planta e maior produtividade de grãos do que as cultivares destinadas ao baixo investimento.
\end{abstract}

Termos para indexação: Zea mays, sistemas de produção, arranjamento de plantas, densidade de semeadura, adubação.

\section{ABSTRACT}

With the aim of evaluating the agronomic traits in nine maize cultivars, five being considered for cultivation of low investment and four maize crops considered for high investment, two trials were carried out in the agricultural year 2004/2005, in Lavras, MG. One of the trials was carried out with plant density of 55.000 plants ha ${ }^{-1}$ and the other, 65.000 plants ha $^{-1}$. In each trial the nine maize crops were carried out in three fertilizing levels: (1) $300 \mathrm{~kg} \mathrm{ha}^{-1}$ of an 8-28-16 formula at the sowing date, with an additional $200 \mathrm{~kg}$ $\mathrm{ha}^{-1}$ of a 30-00-20 formula, for covering; (2) $400 \mathrm{~kg} \mathrm{ha}^{-1}$ of 8-28-16 at the sowing date, with an additional of 300 kg of 30-00-20, for covering; (3) $500 \mathrm{~kg} \mathrm{ha}^{-1}$ of 8-28-16 at the sowing date, with an additional of $300 \mathrm{~kg} \mathrm{ha}^{-1}$ of 30-00-20 and $150 \mathrm{~kg} \mathrm{ha}^{-1}$ of N, for covering. The results allowed concluding that fertilizing with $500 \mathrm{~kg} \mathrm{ha}^{-1}$ of 8-28-16 at the sowing date, with an additional $300 \mathrm{~kg} \mathrm{ha}^{-1} \mathrm{of}_{30-00-}$ 20 and $150 \mathrm{~kg} \mathrm{ha}^{-1}$ of $\mathrm{N}$, for covering, the maize crops showed expressive increase in the productivity of grains and plant height. The increase of plant density from 55.000 plants ha ${ }^{-1}$ to 65.000 plants ha $^{-1}$ did not influence the productivity of the grains, but interfered in the plant height, ear length, and prolificacy. The maize crops of high input showed higher prolificacy, higher plant height and higher productivity of grains in relationship to the crops of low investment.

Index terms: Zea mays, grain production, arrangement of plantas, density of sowing, fertilizing.

\section{(Recebido em 20 de novembro de 2006 e aprovado em 6 de março de 2008)}

\section{INTRODUÇÃO}

Nos últimos anos, a cultura do milho, no Brasil, vem passando por importantes mudanças no manejo e tratos culturais, o que tem resultado em aumentos significativos na produtividade de grãos. Entre essas mudanças destacam-se a adoção de sementes de cultivares com maior potencial de produção, alterações no espaçamento e na densidade de semeadura de acordo com as características das cultivares e melhoria na qualidade dos solos e na fertilização.
Nos sistemas de produção, os fatores tecnológicos podem ser divididos em "construção da produtividade" e "proteção de produtividade (COELHO et al., 2004). Os fatores de construção da produtividade são: a) genético - cultivares; b) manejo cultural - precisão na semeadura; c) fertilidade do solo, nutrição e adubação; d) clima (água e temperatura). Ênfase é dada aos "fatores de construção da produtividade", pois são esses que aumentam a produtividade em termos de quilogramas por hectare.

\footnotetext{
'Engenheiro Agrônomo, Doutor, Professor - Departamento de Agricultura/DAG - Universidade Federal de Lavras/UFLA - Cx. P. 3037 - $37200-000$ Lavras, MG - renzo@ufla.br

Engenheiro Agrônomo, Mestre - Ministério de Assuntos Campesinos e Agricultura da Bolívia - Direção de Desenvolvimento Tecnológico - Avenida San Martin 1247 - Centro - Yacuiba, Bolivia - arielcanedo@yahoo.es

${ }^{3}$ Engenheiros Agrônomos, Mestres - Fundação de Ensino Superior de Passos - Avenida Juca Stockler, 1130 - 37900-106 - Passos, MG andrehbrito@yahoo.com.br
} 
Pesquisas com avaliação de cultivares, densidades de plantio e adubação evidenciam que, à medida que se eleva a densidade de plantas, são necessárias maiores doses de nutrientes. Por outro lado, com baixa disponibilidade de nutrientes, na qual se espera menor produtividade de grãos, a densidade recomendada deve ser reduzida (MUNDSTOCK, 1977; SILVA et al., 1997).

Entre as formas existentes de manipulação do arranjo espacial, a densidade de plantas é a que tem maior interferência na produção de milho, já que pequenas alterações na população implicam em modificações relativamente grandes na produtividade de grãos. Assim, a produtividade de grãos por unidade de área aumenta com a elevação na densidade de plantas até que o incremento neste, em razão do aumento de plantas, seja inferior ao declínio do rendimento médio por planta (TOLLENAAR \& WU, 1999). A densidade ótima é determinada pela cultivar, pelo ambiente e pelo manejo (SILVA et al., 2003).

A necessidade nutricional das plantas é também um fator que deve ser considerado, quando o objetivo é aumentar a produção de grãos. O milho responde progressivamente à adubação, desde que os demais fatores estejam em níveis ótimos, sendo que o nitrogênio é o nutriente que apresenta maior resposta de aumento de produtividade de grãos (SANGOI et al., 2004). Normalmente, os agricultores que obtêm alta produtividade $\left(\mathrm{Kg} \mathrm{ha}^{-1}\right)$ de milho, aplicam altas doses de fertilizantes $(\mathrm{N}$, $\mathrm{P}, \mathrm{K})$, geralmente acima dos níveis recomendados em suas regiões (COELHO et al., 2004).

Deste modo, pesquisas que visam a avaliar o comportamento agronômico de cultivares de milho em diferentes densidades de semeadura sob diferentes doses de fertilizantes são necessários e podem fornecer valiosas informações aos produtores. Vale ressaltar que há escassez de informações a esse respeito, especificamente na região Sul de Minas Gerais.

Neste trabalho, objetivou-se avaliar o desempenho agronômico de nove cultivares de milho, agrupadas em alto e baixo investimento de acordo com a sua base genética (híbridos simples, triplo, duplo e variedade) sob diferentes níveis de adubação e duas densidades de semeadura.

\section{MATERIALE MÉTODOS}

Os experimentos foram instalados na safra 2004/05 em área experimental do Departamento de Agricultura (DAG) da Universidade Federal de Lavras (UFLA), no município de Lavras/MG, localizado na região Sul do Estado de Minas Gerais, a $920 \mathrm{~m}$ de altitude, $21^{\circ} 14^{\prime}$ de latitude sul e $45^{\circ} 00^{\prime}$ de longitude oeste, em Latossolo Vermelho Escuro distróférrico. $\mathrm{Na}$ área experimental, predomina o sistema de plantio convencional, sendo comum a prática de sucessão de culturas, com o plantio de milho após milho, além disso esta apresentava-se com o solo corrigido e com fertilidade média.

Foram utilizadas nove cultivares de milho, sendo cinco consideradas para cultivo em baixo investimento (uma variedade, dois híbridos duplos e dois híbridos triplos), e quatro cultivares (híbridos simples) consideradas para cultivo sob condições de alto investimento (Tabela 1).

Foram conduzidos dois experimentos sob sistema convencional de plantio, com uma aração e duas gradagens. Em um dos experimentos, utilizou-se a densidade de 55.000 plantas $\mathrm{ha}^{-1}$ e no outro foi utilizado a densidade de 65.000 plantas ha $\mathrm{h}^{-1}$. Em cada experimento as nove cultivares de milho foram avaliadas em três níveis de adubação: (1) 300 $\mathrm{kg} \mathrm{ha}^{-1}$ de 8-28-16 na semeadura, mais $200 \mathrm{~kg} \mathrm{ha}^{-1}$ de 30-0020, em cobertura; (2) $400 \mathrm{~kg} \mathrm{ha}^{-1} \mathrm{de} 8-28-16$ na semeadura, mais $300 \mathrm{~kg} \mathrm{ha}^{-1}$ de 30-00-20, em cobertura; (3) $500 \mathrm{~kg} \mathrm{ha}^{-1}$ de 8-28-16 na semeadura, mais $300 \mathrm{~kg} \mathrm{ha}^{-1}$ de 30-00-20 e 150 $\mathrm{kg} \mathrm{ha}^{-1}$ de uréia, em cobertura. Foi utilizado o delineamento de blocos ao acaso, com três repetições, em esquema fatorial 9 (cultivares) x 3 (níveis de adubação).

Os experimentos foram instalados em 05/11/2004, em áreas contíguas que possuíam características semelhantes de fertilidade do solo e de topografia.

A semeadura foi realizada manualmente em parcelas constituídas de quatro fileiras de cinco metros de comprimento, com espaçamento entre fileiras de $0,80 \mathrm{~m}$. Considerou-se para a coleta de dados as duas linhas centrais. Quando as plantas apresentavam-se com quatro folhas realizou-se o desbaste visando a atingir a densidade avaliada.

As adubações de semeadura e de cobertura foram feitas manualmente, ajustando-se a distribuição do adubo de acordo com cada tratamento. O adubo 30-00-20 (N-P-K) foi aplicado quando as plantas apresentavam entre quatro e seis folhas expandidas. A uréia foi aplicada quando as plantas estavam com cinco a sete folhas totalmente expandidas. As adubações nitrogenadas de cobertura foram feitas a $20 \mathrm{~cm}$ das fileiras de plantas e incorporadas a 3,0 $\mathrm{cm}$ de profundidade.

O controle de plantas daninhas foi realizado quimicamente em pós-emergência, dezoito dias após a semeadura, com aplicação do herbicida atrazina, na dose de 5 litros ha $^{-1}$. A colheita foi realizada manualmente em 30/ 04/2005.

Na área útil da parcela, foram avaliadas as seguintes características: altura de planta $(\mathrm{cm})$, altura de espiga $(\mathrm{cm})$, prolificidade (número de espigas por planta) e produtividade de grãos $\left(\mathrm{kg} \mathrm{ha}^{-1}\right)$ 
Tabela 1 - Características agronômicas das cultivares utilizadas nos experimentos. UFLA, Lavras, MG, 2008.

\begin{tabular}{|c|c|c|c|c|c|c|c|c|}
\hline & Cultivares & Empresas & Tipos & Ciclos & Usos & Cor do grão & 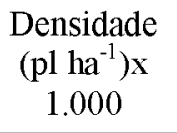 & Textura do grão \\
\hline \multirow{5}{*}{ 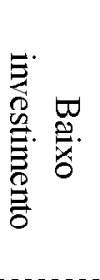 } & $\begin{array}{c}\mathrm{AL} \\
\text { Bandeirante }\end{array}$ & CATI & V & $P$ & $\mathrm{G} / \mathrm{S}$ & AL & $50-55$ & SMDURO \\
\hline & AGN 2012 & Agromen & HD & SP & $\mathrm{G} / \mathrm{S}$ & $\mathrm{AM} / \mathrm{LR}$ & $50-55$ & SMDURO \\
\hline & BRS 3150 & Embrapa & HT & $\mathrm{P}$ & $\mathrm{G} / \mathrm{S}$ & LR/AV & $50-55$ & SMDENT \\
\hline & CD 308 & COODETEC & HD & $\mathrm{P}$ & G & $\mathrm{AL}$ & 50 & SMDURO \\
\hline & GNZ 2005 & Geneze & $\mathrm{HT}$ & $P$ & G & $\mathrm{AL}$ & $55-60$ & SMDURO \\
\hline \multirow{4}{*}{ 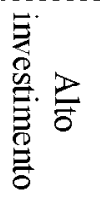 } & DKB 199 & Monsanto & HS & SMP & G & $\mathrm{AM} / \mathrm{AL}$ & $55-65$ & SMDURO \\
\hline & AG 8021 & Monsanto & HS & $\mathrm{P}$ & G & AM/AL & $50-60$ & SMDENT \\
\hline & P 30 F 33 & Pioneer & HS & $P$ & G & $\mathrm{AL}$ & $55-65$ & DURO \\
\hline & GNZ 2004 & Geneze & HS & $\mathrm{P}$ & G/S/MV & $\mathrm{AM} / \mathrm{AL}$ & $50-57$ & SMDENT \\
\hline
\end{tabular}

Legenda: $\mathrm{V}=$ variedade, $\mathrm{HS}$ = híbrido simples, $\mathrm{HD}=$ híbrido duplo, $\mathrm{HT}=$ híbrido triplo, $\mathrm{P}=$ precoce, $\mathrm{SP}=$ superprecoce, $\mathrm{SMP}=$ semiprecoce, $\mathrm{G}=$ grão, $\mathrm{S}=$ silagem, $\mathrm{MV}=$ milho verde, $\mathrm{AL}=$ alaranjado, $\mathrm{AM}=$ amarelo, $\mathrm{LR}=$ laranja, $\mathrm{AV}=$ avermelhado, SMDURO $=$ semiduro, SMDENT $=$ semidentado

Os dados obtidos foram analisados no software estatístico SISVAR. Para comparação das médias foi utilizado o teste de Tukey, a 5\% de probabilidade. Na comparação de contrastes entre as cultivares agrupadas em alto e baixo investimento foi utilizado o teste de Scheffé.

\section{RESULTADOS E DISCUSSÃO}

As cultivares diferiram entre si para todas as características avaliadas. Para os níveis de adubação, as características de prolificidade, altura de planta e produtividade também apresentaram valores de $\mathrm{F}$ significativos. As densidades de semeadura diferiram entre si para a prolificidade, altura de planta e altura de espiga. A interação entre as cultivares e densidades, foi significativa apenas para a característica de prolificidade $(\mathrm{P}=0,01)$. Os coeficientes de variação na maioria das vezes foram inferiores a $10 \%$, comprovando a boa precisão experimental dos experimentos.

A análise de contraste entre as cultivares agrupadas em baixo investimento (cinco cultivares) e alto investimento (quatro cultivares), baseada no teste de Scheffé a 5\% de probabilidade, mostrou que a prolificidade, altura de planta e a produtividade de grãos tiveram resposta estatisticamente significativa (Tabela 2 ). O resultado confirma o verificado em experimentos conduzidos por Carvalho et al. (2002) e Sangoi et al. (2003) quando testaram cultivares de diferentes bases genéticas e comprovaram que os híbridos simples são mais responsivos a melhoria do manejo e, portanto, superam em produtividade a outros tipos de cultivares (variedades, híbridos duplos ou triplos).

A prolificidade apresentou resposta significativa à adubação no nível dois $\left(400 \mathrm{~kg} \mathrm{ha}^{-1}\right.$ de 8-28-16 no plantio, mais $300 \mathrm{~kg} \mathrm{ha}^{-1}$ de 30-00-20 em cobertura) e nível três $\left(500 \mathrm{~kg} \mathrm{ha}^{-1}\right.$ de 8-28-16 no plantio, mais $300 \mathrm{~kg} \mathrm{ha}^{-1} \mathrm{de}$ 30-00-20 em cobertura e mais $150 \mathrm{~kg} \mathrm{ha}^{-1}$ de uréia em cobertura) (Tabela 3). A prolificidade das cultivares destinadas ao alto investimento $(0,997$ espigas por planta) foi superior as de baixo investimento $(0,981$ espigas por planta), segundo a análise de contraste (Tabela 2).

A prolificidade foi influenciada pela densidade (Tabela 4). Na densidade de 55.000 plantas ha-1 as cultivares GNZ 2004, GNZ 2005, P30F33 e CD 308 apresentaram a maior prolificidade. Na densidade de 65.000 plantas $^{-1} \mathrm{a}^{-1}$, a cultivar P30F33 foi a mais prolífica. Na menor densidade $(55.000$ plantas ha-1) foi observado a maior prolificidade (Tabela 4). Esse resultado confirma a afirmação de Dourado Neto et al. (2003) de que o aumento da população de plantas diminui o número de espigas por planta. Sangoi (2001) também observou que os menores índices de prolificidade foram encontrados em maiores populações de plantas. Fornasieri Filho (1992) cita que altas densidades populacionais podem causar alterações morfológicas e fisiológicas, entre elas, o aumento do número de plantas sem espiga.

Os diferentes níveis de adubação influenciaram significativamente a altura de plantas; o nível três de adubação (500 kg ha-1 de 8-28-16 no plantio, mais $300 \mathrm{~kg}$ ha $^{-1}$ de 30-00-20 e $150 \mathrm{~kg} \mathrm{ha}^{-1}$ de uréia em cobertura) proporcionou o maior crescimento das plantas (Tabela 5). 
Tabela 2 - Análise dos contrastes entre cultivares de milho destinados ao baixo investimento (BI) e cultivares destinados ao alto investimento (AI) baseada no teste de Scheffé para as características avaliadas. UFLA, Lavras, MG, 2008.

\begin{tabular}{ccc}
\hline Contraste & Variável & Estimativa do contraste \\
\hline & Prolificidade (espiga por planta) & $-0,0159^{*}$ \\
BI - AI & Altura da planta $(\mathrm{cm})$ & $-9,5417^{*}$ \\
& Altura da espiga $(\mathrm{cm})$ & $-4,6444^{\mathrm{ns}}$ \\
& Produtividade $\left(\mathrm{kg} \mathrm{ha}^{-1}\right)$ & $-1657,9083^{* *}$ \\
\hline
\end{tabular}

*Estimativa significativa a 5\% de probabilidade; $* *$ Estimativa significativa a $1 \%$ de probabilidade; ${ }^{\text {ns }}$ : Estimativa não significativa a $5 \%$ de probabilidade.

Tabela 3 - Médias de prolificidade (número de espigas por planta), em três níveis de adubação, considerando nove cultivares e duas densidades de plantio. UFLA, Lavras, MG, 2008.

\begin{tabular}{cc}
\hline Níveis de adubação* & Médias \\
\hline Nível 1 & 0,95 a \\
Nível 2 & 0,99 b \\
Nível 3 & 0,99 b \\
\hline
\end{tabular}

Médias seguidas pela mesma letra na coluna não diferem pelo teste de Scott-Knott, a 5\% de probabilidade.

* - Nível $1=300 \mathrm{~kg} \mathrm{ha}^{-1} \mathrm{de}$ 8-28-16 (adubação no plantio) + $200 \mathrm{~kg} \mathrm{ha}^{-1}$ de 30-00-20 (adubação em cobertura, 4 a 6 folhas); Nível $2=400 \mathrm{~kg} \mathrm{ha}^{-1}$ de 8-28-16 (adubação no plantio) $+300 \mathrm{~kg} \mathrm{ha}^{-1}$ de 30-00-20 (adubação em cobertura, 4 a 6 folhas); Nível $3=500$ $\mathrm{kg} \mathrm{ha}^{-1}$ de 8-28-16 (adubação no plantio) + $300 \mathrm{~kg} \mathrm{ha}^{-1} \mathrm{de}$ 30-00-20 (adubação em cobertura, 4 a 6 folhas) + $150 \mathrm{~kg} \mathrm{ha}^{-1} \mathrm{de}$ uréia (adubação em cobertura, 6 a 8 folhas).

Tabela 4 - Resultados médios de prolificidade (número de espigas por planta) de nove cultivares de milho em função de duas densidades de plantio, considerando três níveis de adubação. UFLA, Lavras, MG, 2008.

\begin{tabular}{cccc}
\hline Cultivares* $^{*}$ & \multicolumn{2}{c}{ Densidades } & Médias \\
\cline { 2 - 3 } & $55.000 \mathrm{pl} \mathrm{ha}^{-1}$ & $65.000 \mathrm{pl} \mathrm{ha}^{-1}$ & 0,96 \\
Bandeirante $^{(1)}$ & $0,95 \mathrm{a}$ & $0,96 \mathrm{a}$ & 0,97 \\
AGN 2012 $^{(1)}$ & $0,97 \mathrm{a}$ & $0,97 \mathrm{a}$ & 0,98 \\
BRS 3150(1) & $0,99 \mathrm{~b}$ & $0,96 \mathrm{a}$ & 0,99 \\
CD 308 & $1,01 \mathrm{c}$ & $0,98 \mathrm{a}$ & 1,01 \\
GNZ 2005 $^{(1)}$ & $1,03 \mathrm{c}$ & $0,99 \mathrm{a}$ & 0,98 \\
DKB 199 & $0,98 \mathrm{~b}$ & $0,97 \mathrm{a}$ & 0,99 \\
AG 8021 & $0,99 \mathrm{~b}$ & $0,98 \mathrm{a}$ & 1,02 \\
P30F33 & $1,02 \mathrm{c}$ & $1,01 \mathrm{~b}$ & 1,01 \\
GNZ 2004 & $1,04 \mathrm{c}$ & $0,98 \mathrm{a}$ & 0,99 \\
\hline Médias & $1,00 \mathrm{~A}$ & $0,98 \mathrm{~B}$ & \\
\hline
\end{tabular}

Médias seguidas pela mesma letra minúscula na coluna e maiúscula na linha não diferem pelo teste de Scott-Knott, a 5\% de probabilidade. * _ (1) cultivares destinadas ao baixo investimento; ${ }^{(2)}$ cultivares destinadas ao alto investimento.

Entre as cultivares, os híbridos simples GNZ 2004 e AG 8021 foram os que apresentaram a maior altura de plantas, e as cultivares AL Bandeirante e AG 8021 apresentaram maior altura de espiga (Tabela 6). O contraste entre as cultivares agrupadas entre alto e baixo investimento foi significativo para a altura de planta (Tabela 2), sendo que cultivares de alto investimento apresentaram maior altura de planta $(230,7 \mathrm{~cm})$ do que as de baixo investimento $(221,2$ $\mathrm{cm})$. 
Tabela 5 - Médias de altura de planta $(\mathrm{cm})$ em três níveis de adubação, considerando nove cultivares e duas densidades de plantio. UFLA, Lavras, MG, 2008.

\begin{tabular}{cc}
\hline Níveis de adubação* & Médias \\
\hline Nível 1 & 222,15 a \\
Nível 2 & 223,72 a \\
Nível 3 & 230,35 b \\
\hline
\end{tabular}

Médias seguidas pela mesma letra na coluna não diferem pelo teste de Scott-Knott, a 5\% de probabilidade.

Nível 1 = $300 \mathrm{~kg} \mathrm{ha}^{-1}$ de 8-28-16 (adubação no plantio) + $200 \mathrm{~kg} \mathrm{ha}^{-1}$ de 30-00-20 (adubação em cobertura, 4 a 6 folhas); Nível $2=400 \mathrm{~kg}$ ha-1 de 8-28-16 (adubação no plantio) + $300 \mathrm{~kg} \mathrm{ha}^{-1}$ de 30-00-20 (adubação em cobertura, 4 a 6 folhas); Nível $3=500 \mathrm{~kg} \mathrm{ha}^{-1}$ de 8-28-16 (adubação no plantio) + $300 \mathrm{~kg} \mathrm{ha}^{-1}$ de 30-00-20 (adubação em cobertura, 4 a 6 folhas) + $150 \mathrm{~kg} \mathrm{ha}^{-1}$ de uréia (adubação em cobertura, 6 a 8 folhas).

Tabela 6 - Médias de altura de planta $(\mathrm{cm})$ e de altura de espiga $(\mathrm{cm})$ de nove cultivares avaliadas em duas densidades de plantio e três níveis de adubação. UFLA, Lavras, MG, 2008.

\begin{tabular}{|c|c|c|}
\hline Cultivares* & Alturas de planta & Alturas de espigas \\
\hline CD $308^{(1)}$ & 207,06 a & $104,94 \mathrm{a}$ \\
\hline P30F33 ${ }^{(2)}$ & $213,11 \mathrm{a}$ & $112,11 \mathrm{~b}$ \\
\hline AGN $2012^{(1)}$ & 213,83 a & 106,44 a \\
\hline BRS $3150^{(1)}$ & $226,78 \mathrm{~b}$ & $105,94 \mathrm{a}$ \\
\hline GNZ $2005^{(1)}$ & $227,94 \mathrm{~b}$ & $112,06 \mathrm{~b}$ \\
\hline DKB $199^{(2)}$ & $230,17 \mathrm{~b}$ & $113,83 \mathrm{~b}$ \\
\hline Bandeirante $^{(1)}$ & $230,22 \mathrm{~b}$ & $124,06 \mathrm{c}$ \\
\hline AG $8021^{(2)}$ & $235,72 \mathrm{c}$ & $122,72 \mathrm{c}$ \\
\hline GNZ $2004^{(2)}$ & $243,83 \mathrm{c}$ & $112,67 \mathrm{~b}$ \\
\hline
\end{tabular}

Médias seguidas pela mesma letra na coluna não diferem pelo teste de Scott-Knott, a 5\% de probabilidade.

* _ (1) cultivares destinadas ao baixo Investimento; ${ }^{(2)}$ cultivares destinadas ao alto investimento.

$\mathrm{Na}$ densidade de 55.000 plantas $\mathrm{ha}^{-1}$ a altura das planta e de espiga (Tabela 7) foi maior que na densidade de 65.000 plantas $\mathrm{ha}^{-1}$. Isso ocorreu, provavelmente, em razão da menor competição entre as plantas por água, nutrientes e luz.

A maioria das cultivares disponíveis no mercado é de porte médio e ou baixo. Isto tem proporcionado uma maior eficiência na utilização da radiação solar, permitindo maior tolerância a altas densidades de semeadura. Borém (1998) afirma que plantas baixas com folhas eretas acima da espiga, é uma característica desejável para atingir essa eficiência e maior tolerância à altas densidades de semeadura.

A maior produtividade de grãos foi obtida no nível de adubação três (500 $\mathrm{kg} \mathrm{ha}^{-1}$ de 8-28-16 no plantio, mais $300 \mathrm{~kg} \mathrm{ha}^{-1}$ de 30-00-20 e $150 \mathrm{~kg} \mathrm{ha}^{-1}$ de uréia em cobertura) (Tabela 8). Esse resultado evidencia que o aumento na dose de adubo na semeadura e em cobertura proporciona um aumento na produtividade de grãos de aproximadamente $9,5 \%$; também revela a importância do incremento na adubação nitrogenada para o aumento da produtividade de grãos de milho.

A área onde foram conduzidos os experimentos apresentava boa fertilidade, com alto teor de fósforo, percentagem de matéria orgânica média e nível de potássio considerado baixo. Portanto, os suprimentos de adubo na semeadura e na cobertura coadjuvaram na obtenção de altas produtividades. Vale ressaltar que, na área experimental foi adotado o sistema convencional de plantio, com sucessão de cultivo, sendo plantio de milho após milho.

A cultivar P30F33 foi a de maior produtividade de grãos (Tabela 9). É importante salientar que essa cultivar está agrupada dentro das recomendadas para áreas de alto investimento, sendo um híbrido simples, o que ressalta o potencial genético desse tipo de cultivar, frente às outras. Silva et al. (2004) afirmam que a diferença na produtividade de grãos entre cultivares de diferentes bases genéticas é acentuada à medida que se melhora o manejo. 
Tabela 7 - Médias de altura de planta $(\mathrm{cm})$ e de altura de espiga $(\mathrm{cm})$ em duas densidades de plantio, considerando nove cultivares de milho e três níveis de adubação. UFLA, Lavras, MG, 2008.

\begin{tabular}{ccc}
\hline Densidades de plantio & Alturas de planta & Alturas de espigas \\
\hline 65.000 plantas ha $^{-1}$ & $218,67 \mathrm{a}$ & $108,86 \mathrm{a}$ \\
55.000 plantas ha $^{-1}$ & $232,15 \mathrm{~b}$ & $116,64 \mathrm{~b}$ \\
\hline
\end{tabular}

Médias seguidas pela mesma letra na coluna não diferem pelo teste de $\mathrm{F}$, a 5\% de probabilidade.

Tabela 8 - Médias de produtividade de grãos $\left(\mathrm{kg} \mathrm{ha}^{-1}\right)$ em três níveis de adubação, considerando nove cultivares e duas densidades de plantio. UFLA, Lavras, MG, 2008.

\begin{tabular}{cc}
\hline Níveis de adubação* & Médias \\
\hline Nível 1 & $8.826,94$ a \\
Nível 2 & $9.069,39$ a \\
Nível 3 & $9.671,11 \mathrm{~b}$ \\
\hline
\end{tabular}

Médias seguidas pela mesma letra na coluna, não diferem pelo teste de Scott-Knott, a 5\% de probabilidade.

Nível 1 = $300 \mathrm{~kg} \mathrm{ha}^{-1}$ de 8-28-16 (adubação no plantio) + $200 \mathrm{~kg} \mathrm{ha}^{-1}$ de 30-00-20 (adubação em cobertura, 4 a 6 folhas); Nível $2=$ $400 \mathrm{~kg} \mathrm{ha}^{-1}$ de 8-28-16 (adubação no plantio) + $300 \mathrm{~kg} \mathrm{ha}^{-1}$ de 30-00-20 (adubação em cobertura, 4 a 6 folhas); Nível $3=500 \mathrm{~kg}$ ha-1 de 8-28-16 (adubação no plantio) + $300 \mathrm{~kg} \mathrm{ha}^{-1}$ de 30-00-20 (adubação em cobertura, 4 a 6 folhas) $+150 \mathrm{~kg} \mathrm{ha}^{-1}$ de uréia (adubação em cobertura, 6 a 8 folhas).

Tabela 9 - Médias de produtividade de grãos $\left(\mathrm{kg} \mathrm{ha}^{-1}\right)$ de nove cultivares de milho avaliadas em duas densidades de plantio e três níveis de adubação. UFLA, Lavras, MG, 2008.

\begin{tabular}{|c|c|}
\hline Cultivares* & Médias \\
\hline Bandeirante $^{(1)}$ & $7.853,72 \mathrm{a}$ \\
\hline AGN $2012^{(1)}$ & $8.211,17 \mathrm{a}$ \\
\hline BRS $3150^{(1)}$ & $8.267,44$ a \\
\hline GNZ $2005^{(1)}$ & $8.961,67 \mathrm{~b}$ \\
\hline CD $308^{(1)}$ & $8.967,50 \mathrm{~b}$ \\
\hline DKB $199^{(2)}$ & $9.259,28 \mathrm{~b}$ \\
\hline AG $8021^{(2)}$ & $10.130,39 \mathrm{c}$ \\
\hline GNZ $2004^{(2)}$ & $10.253,28 \mathrm{c}$ \\
\hline P30F33 ${ }^{(2)}$ & $10.797,89 \mathrm{~d}$ \\
\hline
\end{tabular}

Médias seguidas pela mesma letra na coluna não diferem pelo teste de Scott-Knott, a 5\% de probabilidade.

* _ ${ }^{(1)}$ cultivares destinadas ao baixo investimento; ${ }^{(2)}$ cultivares destinadas ao alto investimento.

O contraste entre as médias das cultivares agrupadas em alto e baixo investimento foi significativo (Tabela 2), evidenciando a maior produtividade do grupo de alto investimento $\left(10.110 \mathrm{~kg} \mathrm{ha}^{-1}\right)$ frente as de baixo investimento $\left(8.452 \mathrm{~kg} \mathrm{ha}^{-1}\right)$. A estimativa do contraste foi de $1657,9 \mathrm{~kg}$, o que representa quase $20 \%$ a mais na produtividade de grãos. Médias de produtividade de cultivares destinadas a áreas de alto investimento são claramente superiores às medias das cultivares destinadas a cultivos com baixo investimento (BACKES et al., 2004; MENDES et al., 2004).
Neste trabalho, foi verificado que o grupo de cultivares de alto investimento apresentou maior produtividade de grãos, expressando o seu maior potencial genético. Este fato também confirma a razão do crescimento, no Brasil, do uso de sementes de cultivares destinadas ao alto investimento que, nos últimos anos, teve a venda de sementes aumentada significativamente. Isso evidencia a importância do investimento em tecnologia para aumentar a produtividade de milho no Brasil, o que significará maior lucratividade para o agricultor. 
Os resultados obtidos permitem afirmar que a melhoria na tecnologia de produção é o diferencial para o agricultor que produz com padrões tecnológicos elevados, permitindo a obtenção de altas produtividades de grãos.

\section{CONCLUSÕES}

A utilização de $500 \mathrm{~kg} \mathrm{ha}^{-1}$ de 8-28-16 no plantio, mais $300 \mathrm{~kg} \mathrm{ha}^{-1}$ de 30-00-20 na primeira cobertura e $150 \mathrm{~kg}$ $\mathrm{ha}^{-1}$ de uréia na segunda cobertura, proporciona aumento significativo na produtividade de grãos e na altura das plantas.

O aumento da densidade de semeadura de 55.000 plantas ha ${ }^{-1}$ para 65.000 plantas ha ${ }^{-1}$ não influencia a produtividade de grãos, mas interfere na altura de plantas e de espigas e na prolificidade.

O híbrido simples P30F33 foi o mais produtivo, independentemente do nível de adubação e da densidade de semeadura.

As cultivares destinadas ao alto investimento apresentam maior prolificidade, maior altura de planta e maior produtividade de grãos do que as cultivares destinadas ao baixo investimento.

\section{REFERÊNCIAS BIBLIOGRÁFICAS}

BACKES, R. L.; BALBINOT JUNIOR, A. A.; VIEIRA, L. C.; TÔRRES, A. N. L.; SOUZA, A. M. Desempenho agronômico de híbridos, variedades de polinização aberta e segunda geração de híbrido de milho em dois níveis de investimento. In: CONGRESSO NACIONAL DE MILHO E SORGO, 25., 2004, Cuiabá, MT. Resumos... Sete Lagoas: ABMS/Embrapa Milho e Sorgo/Empaer, 2004. p. 299.

BORÉM, A. Melhoramento de plantas. 2. ed. Viçosa: UFV, 1998. $453 \mathrm{p}$.

CARVALHO, H. W. L.; LEAL, M. L. S.; CARDOSO, M. J. Adaptabilidade e estabilidade de cultivares de milho no nordeste brasileiro no triênio 1998 a 2000. Pesquisa Agropecuária Brasileira, Brasília, v. 37, p. 1581-1588, 2002.

COELHO, A. M.; CRUZ, J. C.; PEREIRA FILHO, I. A. Desafios para obtenção de altas produtividades de milho. In: CONGRESSO NACIONAL DE MILHO E SORGO, 25., 2004, Cuiabá. Palestras... Cuiabá: ABMS/Embrapa Milho e Sorgo/Empaer, 2004. CD-ROM.

DOURADO NETO, D.; PALHARES, M.; VIEIRA, P. A.; MANFRON, P. A.; PETTER-MEDEIROS, S. L.;
ROMANO, M. R. Efeito da população de plantas e do espaçamento sobre a produtividade de milho. Revista Brasileira de Milho e Sorgo, [S.1.], v. 2, n. 3, p. 63-77, set./dez. 2003.

FORNASIERI FILHO, D. A cultura do milho. Jaboticabal: Funep, 1992. 273 p.

MENDES, M. C.; PINHO, R. G. von; BRITO, A. H.; FIORINI, F. V. A.; BORGES, I. D. Comportamento de híbridos de milho considerando dois níveis de investimento em LavrasMG. In: CONGRESSO NACIONAL DE MILHO E SORGO, 25., 2004, Cuiabá, MT. Resumos... Sete Lagoas: ABMS/ Embrapa Milho e Sorgo/Empaer, 2004. p. 273.

MUNDSTOCK, C. M. Densidade de semeadura no milho para o Rio Grande do Sul. Porto Alegre: UFRGS/ASCAR, 1977. 35 p.

SANGOI, L. Understanding plant density effects on maize growth and development: an important issue to maximize grain yield. Ciência Rural, Santa Maria, v. 31, n. 1, p. 159168, Jan./Feb. 2001.

SANGOI, L.; HORN, D.; ALMEIDA, M. L. Sistemas de manejo e performance agronômica de cultivares de milho com diferentes bases genéticas no planalto catarinense. In: REUNIÃO TÉCNICA CATARINENSE DE MILHO E FEIJÃO, 4., 2003, Lages. Resumos... Lages: CAV-UDESC, 2003. p. 78.

SANGOI, L.; SILVA, P. R. F. da; ARGENTA, G. Arranjo espacial de plantas de milho: como otimizá-lo para maximizar o rendimento de grãos. In: CONGRESSO NACIONAL DE MILHO E SORGO, 25., 2004, Cuiabá. Palestras... Cuiabá: ABMS/Embrapa Milho e Sorgo/Empaer, 2004.

SILVA, P. R. F. da; ARGENTA, G.; SANGOI, L. Fatores determinantes da escolha da densidade de plantas em milho. In: REUNIÃO TÉCNICA CATARINENSE DE MILHO E FEIJÃO, 4., 2003, Lages, SC. Resumos Expandidos...Lages: CAV-UDESC, 2003. p. 25-29.

SILVA, P. R. F. da; PEIXOTO, C. M.; REZERA, F.; CARMONA, R. C. Produtividade de híbridos de milho em função da densidade de plantas em dois níveis de manejo da água e da adubação. Pesquisa Agropecuária Gaúcha, Porto Alegre, v. 3, n. 1, p. 6371, 1997. 
SILVA, A. A.; SILVA, P. R. F.; ARGENTA, G.; SANGOI, L.; MINETTO, T.; RAMBO, L.; SUHRE, E.; STRIEDER, M. Desempenho agronômico e econômico de tipos de cultivares de milho em função de níveis de manejo. In: CONGRESSO NACIONAL DE MILHO E SORGO, 25., 2004,
Cuiabá. Resumos... Sete Lagoas: ABMS/Embrapa Milho e Sorgo/Empaer, 2004. p. 303.

TOLLENAAR, M.; WU, J. Yield improvement in temperate maize is atributable to greater stress tolerance. Crop Science, Madison, v. 39, n. 6, p. 1597-1604, Nov./Dec. 1999. 